\title{
In-Situ Environmental TEM Study on the Effect of Steam on the Ni Nanoparticles on High Surface Area $\mathrm{TiO}_{2}$
}

\author{
P. Li*, J. Liu**, N. Nag***, and P. A. Crozier* \\ *Center for Solid State Science, Arizona State University, Tempe, AZ 85287-1704, USA \\ **Monsanto Company, 800 N. Lindbergh Blvd., St. Louis, MO 63167, USA \\ ***Process Technology Group, Engelhard Corporation, 23800 Mercantile Road, Beachwood, Ohio \\ 44122, USA
}

Understanding the behavior of metal nanoparticles under oxidizing conditions is very important because supported metal catalysts are used in oxygen and steam environments. The behaviors of metal particles under oxidizing environments can involve long distance migration and coalescence, spreading, splitting and ripening [1]. Metal nanoparticles may undergo a transition and strongly wet the support leading to a possible dispersion of metal species [1]. $\mathrm{Ni} / \mathrm{TiO}_{2}$ catalysts may be used for selective oxidation and the behavior of the Ni nanoparticles under oxidizing environments is not well understood. The present in situ project explores the influence of steam on $\mathrm{Ni} / \mathrm{TiO}_{2}$ catalysts at $600^{\circ} \mathrm{C}$ using a Tecnai F-20 environmental TEM (ETEM).

A Ni/TiO 2 sample was dispersed over Pt grids and put into Tecnai F-20 equipped with an environmental cell. The sample was reduced in situ in 2 Torr of $10 \% \mathrm{H}_{2}$ and $90 \% \mathrm{~N}_{2}$ at $600^{\circ} \mathrm{C}$ for 3 hours. The larger Ni particles $(>8 \mathrm{~nm}$ ) remained relatively stable in this environment (see Figures 1a and 2a). A small quantity of water was then introduced to the cell giving a gas pressure and composition of 2 Torr of $5 \%$ water $/ 9 \% \mathrm{H}_{2} / 86 \% \mathrm{~N}_{2}$ at $600^{\circ} \mathrm{C}$. The Ni nanoparticles immediately began to change when the water was introduced into the cell. Figure 1 shows an $8 \mathrm{~nm} \mathrm{Ni}$ nanoparticle, (that had remained stable for 3 hours under reducing conditions), immediately beginning to shrink when water is introduced. After 5 min water contact, this Ni particle decreased to $7 \mathrm{~nm}$ as shown in Figure 1(b). As time evolves, the Ni particle shrinks its size to about $3 \mathrm{~nm}$ (Figure 1(c)) and finally disappears in Figure 1(d) after only 20 mins. Figure 2 shows another example where a $12 \mathrm{~nm}$ Ni nanoparticle slowly shrinks to about $8 \mathrm{~nm}$ in size while an adjacent bigger Ni particle appears to grow and become more transparent in Figure 2(b).

The Ni nanoparticles start to change only after water admission, demonstrating that the phenomena are related to some chemical transformation in the metal particles. There are several possible explanations for the observed phenomena: (1) Ni oxides or hydroxides may form under water. (2) spreading of the $\mathrm{Ni}$ oxides on the titania support driven by the stronger interaction between the $\mathrm{Ni}$ oxides and the titania support and the lower surface free energy of the Ni oxides comparing to Ni. (3) smaller particles may be easier to oxidize and spread more quickly on the support. (4) ripening mechanisms facilitated by water may cause the smaller particles to shrink and disappear. These mechanisms will be discussed in greater details and similar measurements from other metals will be considered.

References

[1] G. B. Raupp et al., Metal-Support Interactions in Catalysis, Sintering, and Redispersion, 1987, Van Nostrand Reinhold Company Inc., New York 


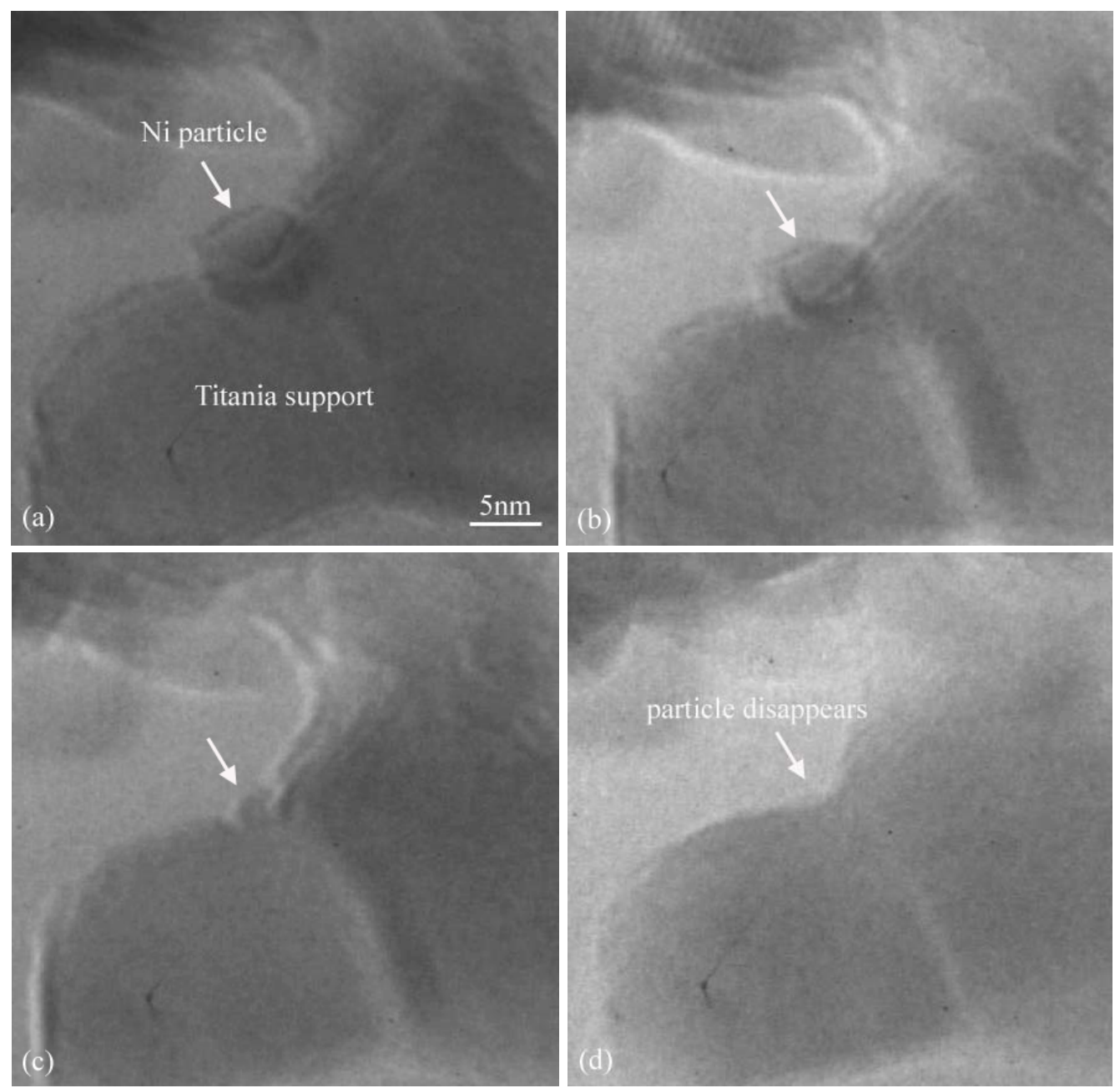

FIG. 1. In-situ TEM images showing the dynamic behavior of the Ni particles (a) before and after staying under 2 Torr of $5 \%$ water $/ 9 \% \mathrm{H}_{2} / 86 \% \mathrm{~N}_{2}$ at $600^{\circ} \mathrm{C}$ for (b) $5 \mathrm{~min}$, (c) $10 \mathrm{~min}$ (d) $20 \mathrm{~min}$.
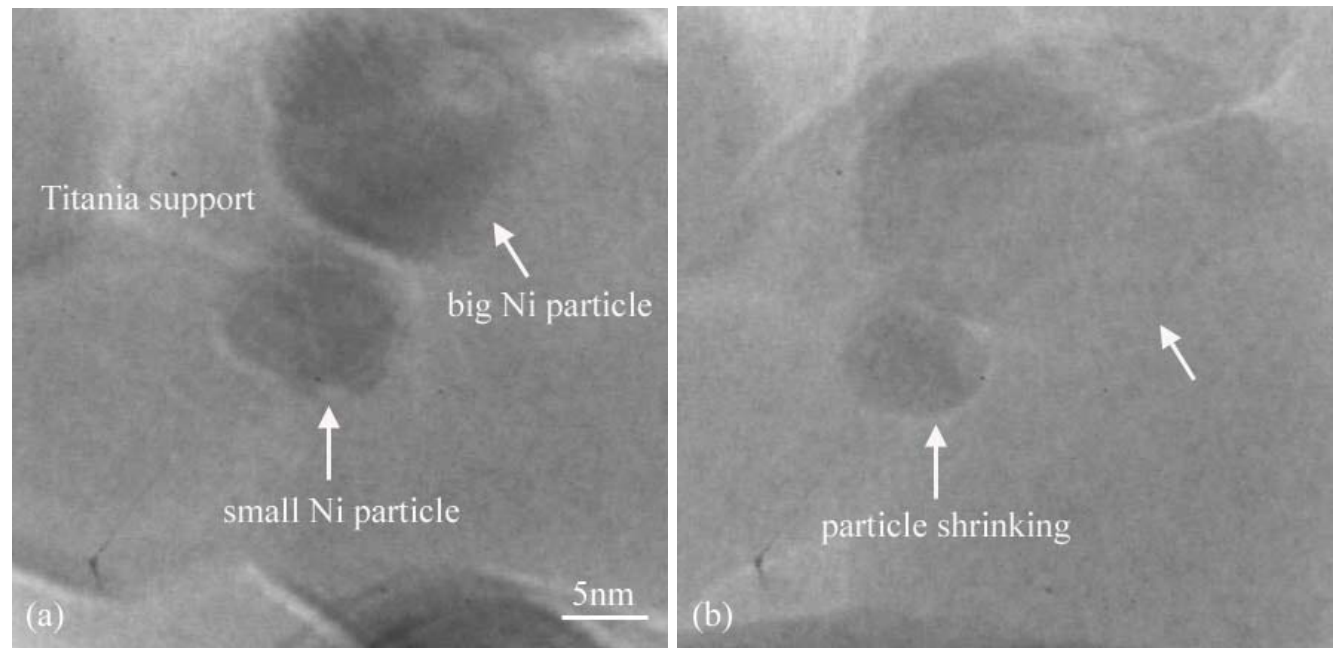

FIG. 2. In-situ TEM images showing the behavior of the Ni nanoparticles (a) before and (b) after staying under 2 Torr of $5 \%$ water $/ 9 \% \mathrm{H}_{2} / 86 \% \mathrm{~N}_{2}$ at $600^{\circ} \mathrm{C}$ for $40 \mathrm{~min}$. 